\title{
Synthesis of tripodal catecholates and their immobilization on zinc oxide nanoparticles
}

\author{
Franziska Klitsche ${ }^{1}$, Julian Ramcke ${ }^{1}$, Julia Migenda ${ }^{2}$, Andreas Hensel ${ }^{3}$, \\ Tobias Vossmeyer ${ }^{3}$, Horst Weller ${ }^{3}$, Silvia Gross ${ }^{*}$ and Wolfgang Maison ${ }^{* 1}$
}

Full Research Paper

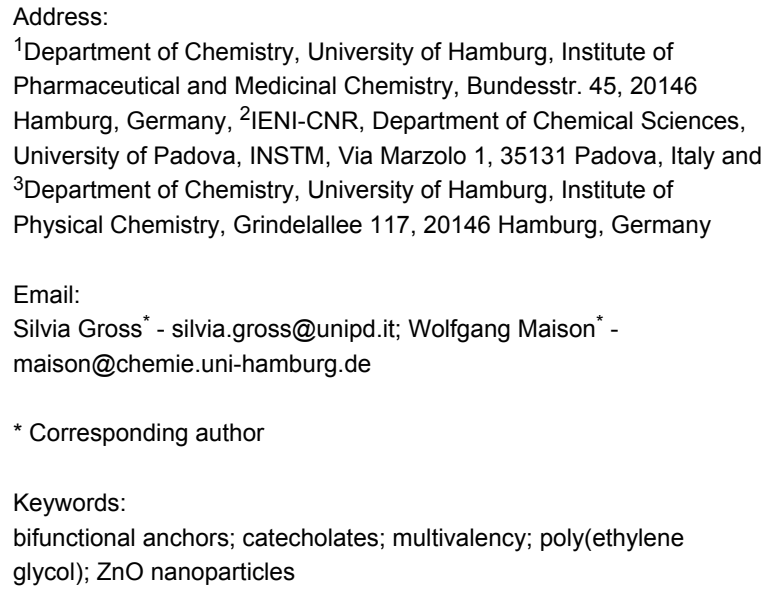

${ }^{1}$ Department of Chemistry, University of Hamburg, Institute of Pharmaceutical and Medicinal Chemistry, Bundesstr. 45, 20146 Hamburg, Germany, ${ }^{2}$ IENI-CNR, Department of Chemical Sciences, University of Padova, INSTM, Via Marzolo 1, 35131 Padova, Italy and ${ }^{3}$ Department of Chemistry, University of Hamburg, Institute of Physical Chemistry, Grindelallee 117, 20146 Hamburg, Germany

\section{Email:}

Silvia Gross* - silvia.gross@unipd.it; Wolfgang Maison* -

maison@chemie.uni-hamburg.de

* Corresponding author

Keywords:

bifunctional anchors; catecholates; multivalency; poly(ethylene glycol); ZnO nanoparticles

\author{
Beilstein J. Org. Chem. 2015, 11, 678-686. \\ doi:10.3762/bjoc. 11.77 \\ Received: 02 March 2015 \\ Accepted: 27 April 2015 \\ Published: 07 May 2015 \\ This article is part of the Thematic Series "Multivalency as a chemical \\ organization and action principle". \\ Guest Editor: R. Haag \\ (c) 2015 Klitsche et al; licensee Beilstein-Institut. \\ License and terms: see end of document.
}

\begin{abstract}
A common approach to generate tailored materials and nanoparticles (NPs) is the formation of molecular monolayers by chemisorption of bifunctional anchor molecules. This approach depends critically on the choice of a suitable anchor group. Recently, bifunctional catecholates, inspired by mussel-adhesive proteins (MAPs) and bacterial siderophores, have received considerable interest as anchor groups for biomedically relevant metal surfaces and nanoparticles. We report here the synthesis of new tripodal catecholates as multivalent anchor molecules for immobilization on metal surfaces and nanoparticles. The tripodal catecholates have been conjugated to various effector molecules such as PEG, a sulfobetaine and an adamantyl group. The potential of these conjugates has been demonstrated with the immobilization of tripodal catecholates on $\mathrm{ZnO}$ NPs. The results confirmed a high loading of tripodal PEG-catecholates on the particles and the formation of stable PEG layers in aqueous solution.
\end{abstract}

\section{Introduction}

An elegant approach to generate tailored materials and nanoparticles is the formation of molecular monolayers by chemisorption of bifunctional anchor molecules (Figure 1A) [1]. The effectivity of this approach depends critically on the choice of a suitable anchor molecule. For most applications the anchor needs to be modular and should have functional groups for conjugation of effector molecules via high-yielding and robust chemical transformations. On the other hand, the anchor moiety needs to form a stable (in most cases covalent) connection to the target surface. Various bifunctional anchors have been reported for immobilization on different materials and nanoparticles. Basically, silane derivatives are used for glass surfaces $[2,3]$, thiols for noble metal surfaces [4], carboxylates [5] and phosphates [6] as well as phosphonates [7] for metal and metal 
oxide surfaces. In addition, bifunctional catechols like dopamine or DOPA (L-3,4-dihydroxyphenylalanine, Figure 1B), have received considerable interest as anchor groups for important metal surfaces such as titanium oxide, iron oxide and stainless steel [8-11]. Immobilization of catecholates was inspired by mussel-adhesive proteins (MAPs) and bacterial siderophores [12].

However, many applications of catecholate immobilization in physiological media are compromised by continuous leaching of grafted material which is a consequence of reversible binding at neutral and slightly acidic $\mathrm{pH}$. Multivalent catecholates, such as MAPs or oligo-DOPA, overcome this drawback of simple catecholate derivatives and show increased binding affinities to metal surfaces. They are therefore attractive anchors for durable immobilizations on metal surfaces in aqueous media [13]. We have recently reported non-peptidic trimeric catecholates and have demonstrated their potential to form stable molecular monolayers on bulk $\mathrm{TiO}_{2}$ and stainless steel surfaces in aqueous environment $[14,15]$. In the present work, we describe the synthesis of effector-conjugates of tripodal catecholates and their immobilization on ZnO NPs.

\section{Results and Discussion}

Zinc oxide belongs to the most intensively investigated inorganic compounds, due to its outstanding functional properties combined with manifold morphologies, no toxicity and easy preparation [16]. It is a piezoelectronic semiconductor with a high exciton binding energy (60 meV) and a wide band-gap $(3.37 \mathrm{eV})$ at room temperature $[17,18] . \mathrm{ZnO}$ is therefore employed in (bio-)sensors [19], ultraviolet (UV) light-emitting diodes [20], UV laser diodes [21] and in the field of catalysis $[22,23]$. $\mathrm{ZnO}$ exists in several morphologies such as nanowires, nanotubes, nanoparticles, nanoplatelets and nanowhiskers [24]. Colloidal $\mathrm{ZnO}$ nanoparticles are especially interesting because of their functional properties. Classical methods of colloid chemistry can be used for the preparation of colloidal suspensions [25] and various paths to obtain $\mathrm{ZnO}$ colloids have been reviewed by Spanhel [26]. Suitable methods for the synthesis of pure and doped ZnO NPs involve colloidal, sol-gel or solvo-/ hydrothermal methods [27], microemulsion and miniemulsion methods [28] or non-aqueous sol-gel routes [29]. Recently, some of us established an easy and fast procedure to obtain nanocrystalline $\mathrm{ZnO}$ nanoparticles, which was applied to prepare the $\mathrm{ZnO}$ nanoparticles used in this work [30].

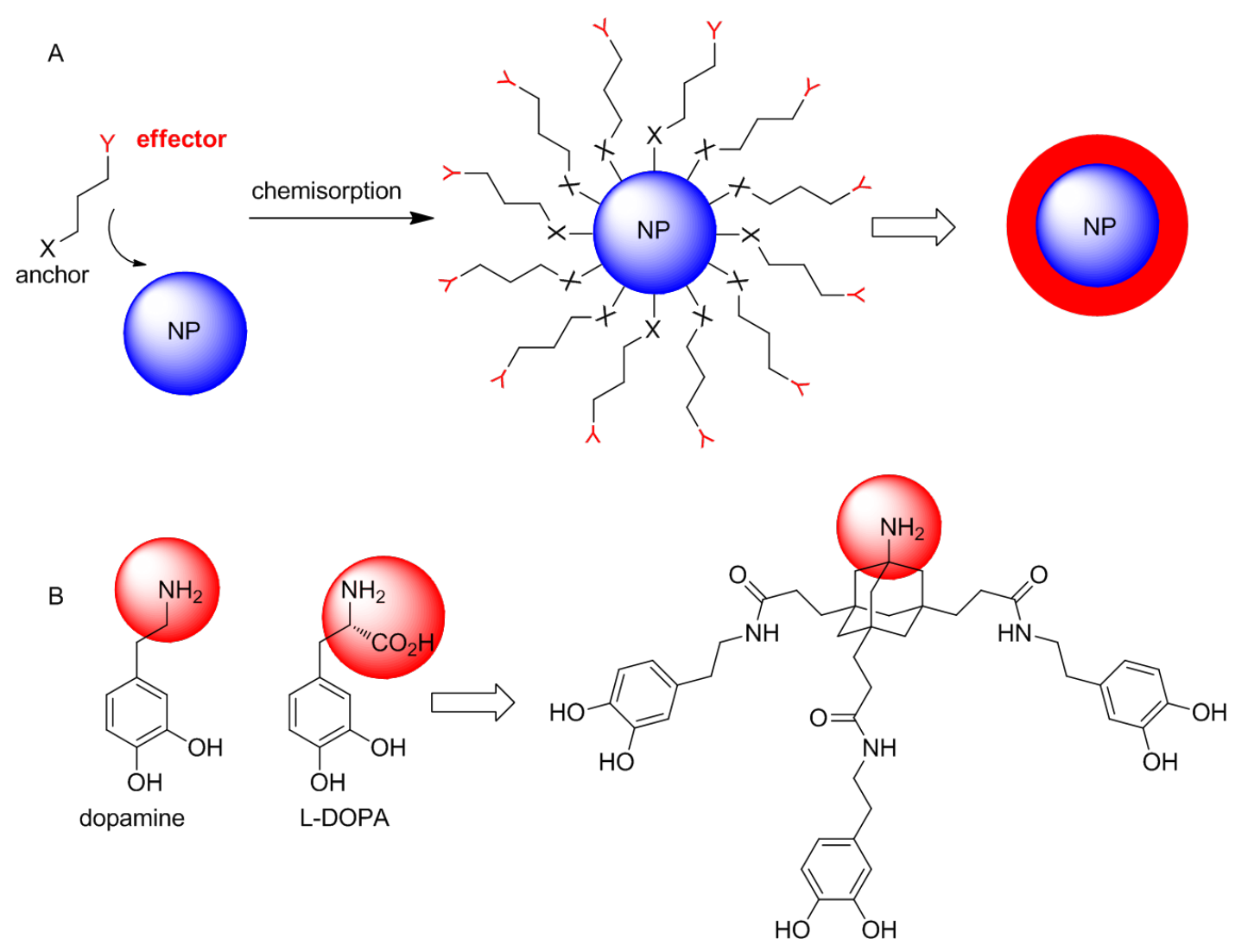

Figure 1: A) Schematic drawing of a bifunctional anchor molecule and its immobilization on a nanoparticle (NP); B) tripodal catechol derivative, derived from the native bifunctional anchors dopamine and L-DOPA. 
Immobilization of effector molecules on $\mathrm{ZnO}$ NPs has been accomplished with oxygen donors such as carboxylic acids. Bifunctional derivatives bearing an additional effector moiety may be used to generate stable particles with tailored properties, good solubility and biocompatibility. Suitable effectors in this context are PEG [31-33], zwitterions [34,35] or polyglycerols $[36,37]$ which, when immobilized on NPs, may be used to tune their pharmacokinetic properties [38,39]. The resulting particles show a reduced tendency towards plasma protein and tissue binding, both important factors influencing elimination and tissue distribution of biological imaging reagents. Based on our good experiences with the immobilization of tripodal catecholates on $\mathrm{TiO}_{2}$ and steel, we explored their use for the functionalization of $\mathrm{ZnO}$ NPs.

\section{Synthesis of tripodal catecholates}

A common synthetic precursor for the synthesis of suitable tripodal catecholates is the $\mathrm{AB}_{3}$-scaffold 1 [40-42] (Scheme 1)

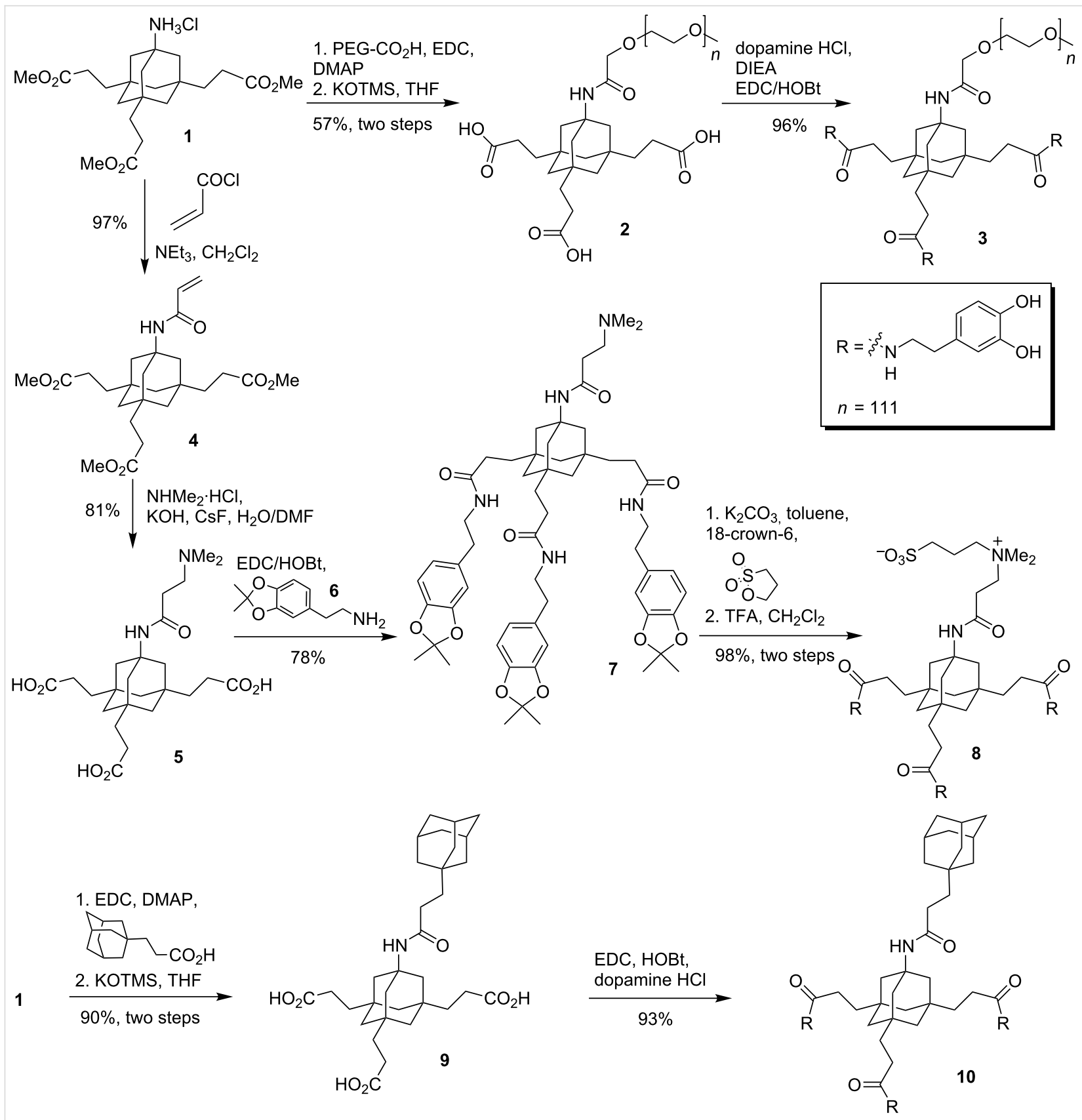

Scheme 1: Synthesis of tripodal catecholates for surface immobilization. PEG-triscatecholate 3 was synthesized from 1 according to literature [31]. Abbreviations: $\mathrm{PEG}=$ poly(ethylene glycol) $(5 \mathrm{kDa})$; EDC = 1-ethyl-3-(3-dimethylaminopropyl)carbodiimide; DMAP = 4-(dimethylamino)pyridine; $\mathrm{HOBt}=$ hydroxybenzotriazole; TFA = trifluoroacetic acid, KOTMS = potassium trimethylsilanolate, DIEA = N,N-diisopropylethylamine. 
which is readily available in a few steps from adamantane as a cheap starting material [43]. Amine 1 was coupled to a commercially available PEG-carboxylate $(5 \mathrm{kDa})$ with EDC/ DMAP. The resulting PEG-conjugate was treated with KOTMS to remove the methyl esters to give tricarboxylic acid $\mathbf{2}$ in good $57 \%$ yield for the two-step procedure. In a last step, dopamine was coupled to the free carboxylic acids to give PEG-triscatecholate 3 in excellent yield [31]. This PEG-conjugate is ready for the immobilization on NPs and may be used to generate biopassive (stealth) particles for biomedical applications.

As an alternative to PEG as an effector moiety, we tried to conjugate the triscatecholates to a sulfobetaine group. Like PEG, these zwitterionic moieties have been used frequently to confer biopassive properties to metal surfaces but are less prone to oxidative degradation [35]. The synthesis started again from $\mathrm{AB}_{3}$-scaffold 1 which was acylated with acryloyl chloride to give acrylamide 4 . Treatment of $\mathbf{4}$ with dimethylamine and excess $\mathrm{KOH}$ leads to the nucleophilic addition of the amine and saponification of the methyl esters in one step to give the free acid 5 after acidic work-up. Subsequent coupling of 5 to dopamine acetonide $\mathbf{6}$ with EDC and HOBt gave the protected triscatecholate 7 in good yield. The sulfobetaine was then generated by treatment of 7 with 1,3-propane sultone and the acetonides were cleaved with TFA to give the free triscatecholate 8. Following the same synthetic strategy, the hydrophobic derivative $\mathbf{1 0}$ bearing an additional adamantyl group as an effector was prepared. This triscatecholate might be useful for the construction of diamandoid hydrophobic coatings [44] or for the reversible attachment of cyclodextrins to NPs by the formation of cyclodextrin/adamantane inclusion complexes [45].
Alternatively, acrylamide 4 and bromide 12 [42] were converted to the corresponding triscatecholates 11 and $\mathbf{1 3}$ by coupling to dopamine (Scheme 2). The resulting triscatecholates $\mathbf{1 1}$ and $\mathbf{1 3}$ may be used as synthetically flexible platforms for functionalizations of surfaces via either nucleophilic addition (to the Michael acceptor in 11) or radical chemistry after immobilization.

\section{Immobilization on ZnO NPs}

Three different catecholates were selected to study the binding properties to $\mathrm{ZnO}$ NPs (Figure 2). Monomeric PEG-catecholate 14 [46] and the tripodal homologue 3 were chosen to study the stability of the coatings and the particles in aqueous solution depending on the valency of the catecholate. Bromotriscatecholate $\mathbf{1 3}$ was chosen as a hydrophobic analogue to $\mathbf{3}$.

$\mathrm{ZnO}$ particles were synthesized according to a literature known procedure from $\mathrm{Zn}(\mathrm{acac})_{2}$ [30].

Powders separated by the centrifugation of the precursor suspensions were investigated by X-ray diffraction to confirm the formation of crystalline materials. The XRD pattern confirms the selective formation of pure $\mathrm{ZnO}$ wurtzite already at room temperature without the need of any further thermal treatment (Figure 3A). This data is in agreement with TEM micrographs, indicating the presence of spherical particles with an average diameter of $6 \mathrm{~nm}$ next to larger crystal aggregates (Figure 3B).

The particles were coated using solutions of monomeric PEGcatecholate $\mathbf{1 4}$ and the tripodal catecholates $\mathbf{3}$ and $\mathbf{1 3}$ in a concentrated 3-morpholinopropanesulfonic acid (MOPS) buffer

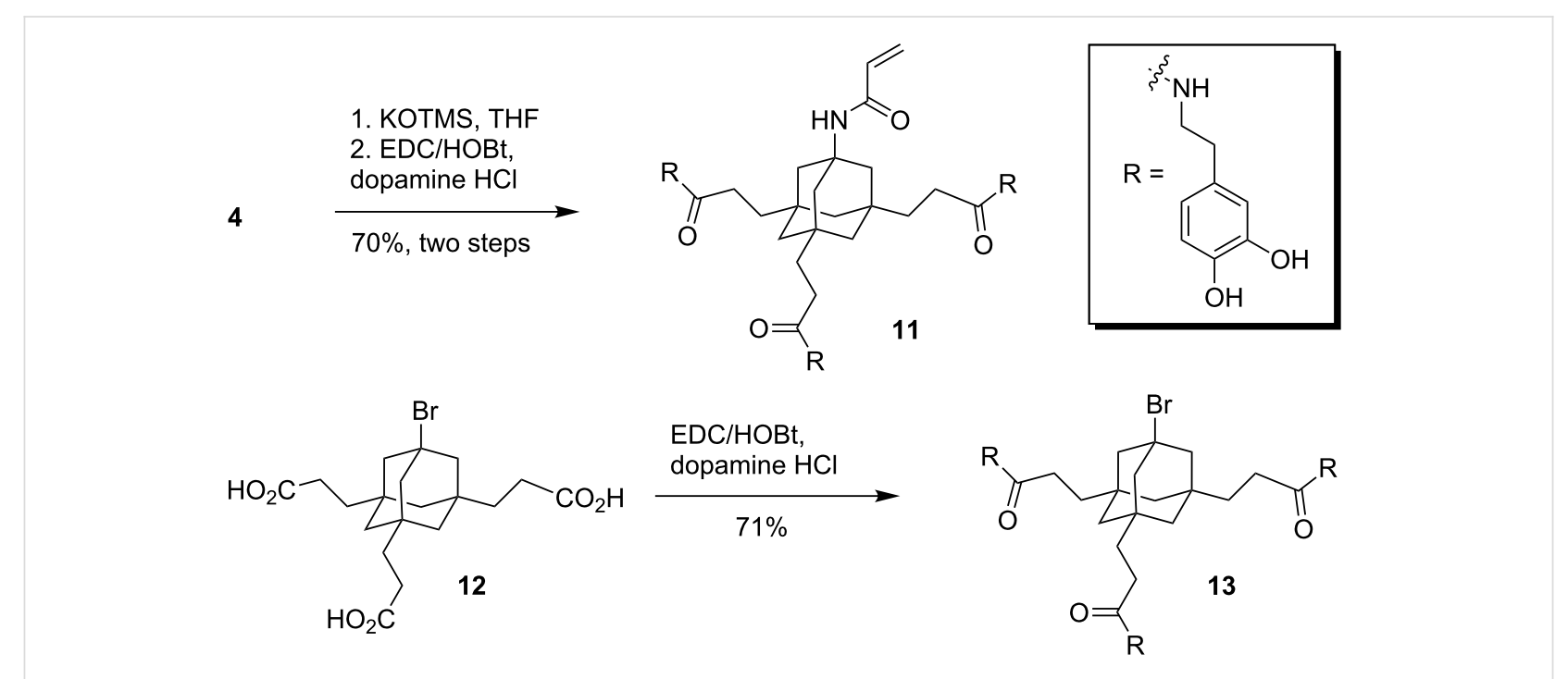




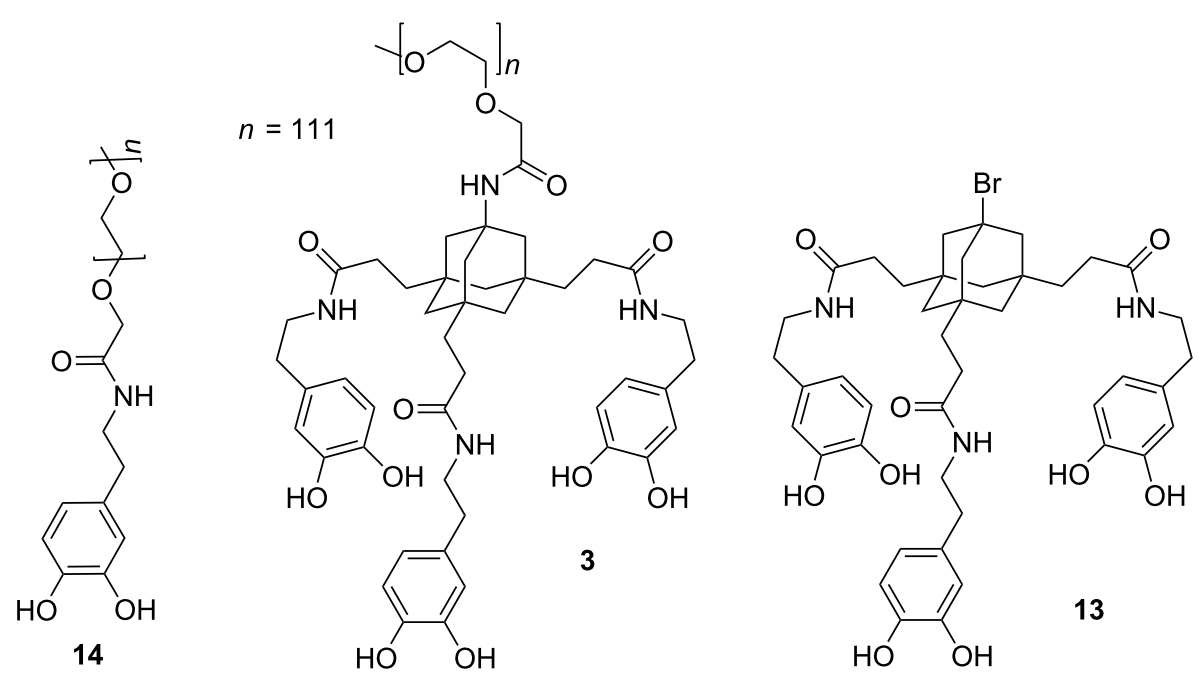

Figure 2: Catecholates for the immobilization on $\mathrm{ZnO}$ NPs.
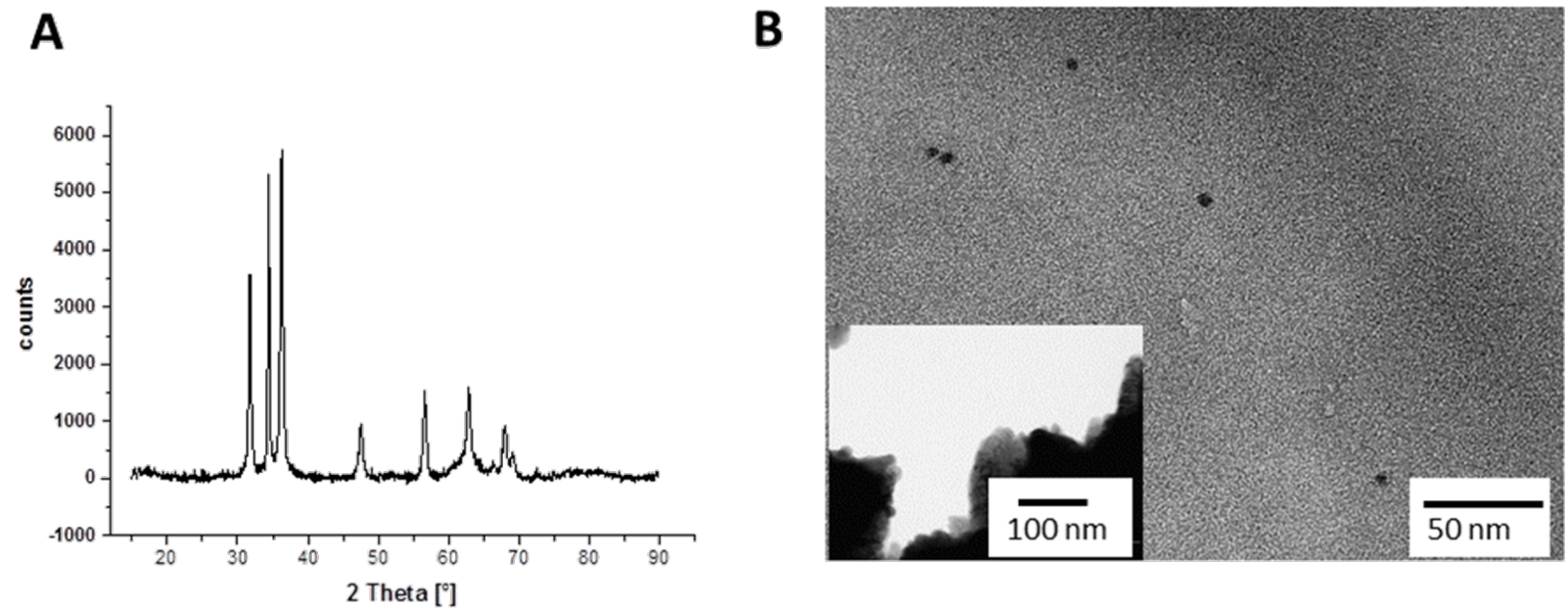

Figure 3: A) XRD pattern of ZnO NPs obtained by the colloidal suspension of $\mathrm{Zn}(\mathrm{acac})_{2}$. B) TEM image of pure $\mathrm{ZnO}$ nanoparticles.

at $\mathrm{pH} 10$ [14,31]. Under these conditions, the catechol moieties were reasonably stable and only small amounts $(5 \%)$ of the corresponding oxidized quinones were detectable by NMR in the solutions after $24 \mathrm{~h}$. The ZnO NPs were treated with the buffered catecholate solutions for $12 \mathrm{~h}$, isolated by centrifugation, washed with a small amount of water $(\mathrm{pH} 7)$ and $\mathrm{MeOH}$ and freeze-dried before analysis by XRD, IR, HRTEM-EDX and TGA. A reference probe of ZnO NPs was treated the same way, but no catecholate was added to the buffer.

3-Morpholinopropanesulfonate, the ingredient of the MOPS buffer, showed only a weak affinity for $\mathrm{ZnO}$ NPs according to the corresponding TGA curve in Figure $4 \mathrm{~A}$ and EDX (Figure $4 \mathrm{C}$ ). Sulfonates have been described as $\mathrm{ZnO}$ binders before $[47,48]$. However, the binding affinity of 3-morpholinopropanesulfonate to $\mathrm{ZnO}$ NPs is low and most of the ligand is eliminated by washing following the immobilization.

In contrast, TGA indicated a high loading of the particles with both the monomeric PEG-catecholate 14 (48 wt \% loading) and the tripodal catecholates 3 (70 wt \% loading) and $\mathbf{1 3}$ (17 wt \% loading). The latter two values are close to the theoretical maximum loading of $63 \mathrm{wt} \%$ (for 3 ) and $20 \mathrm{wt} \%$ (for 13 , note the dramatically lower mass of $\mathbf{1 3}$ compared to PEG-conjugates 3 and 14), which was calculated for an ideal particle of $6 \mathrm{~nm}$ diameter and $0.25 \mathrm{~nm}^{2}$ coverage per catecholate residue [49]. The loading of monomeric PEG-catecholate 14 on $\mathrm{ZnO}$ NPs is significantly lower compared to the calculated maximum 
A

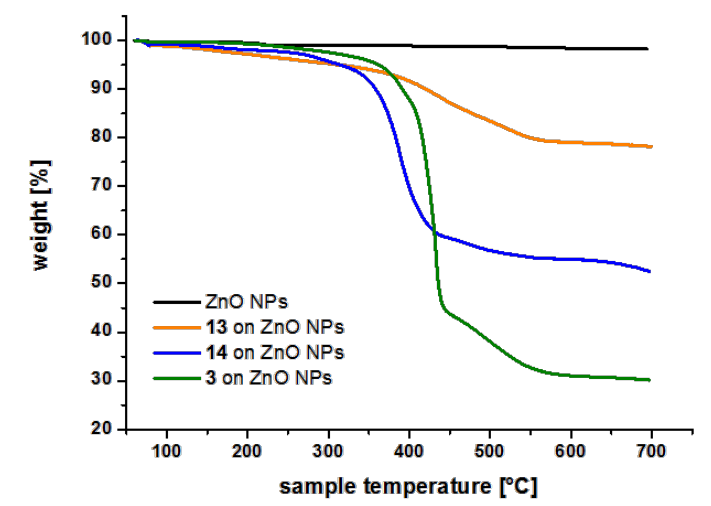

B

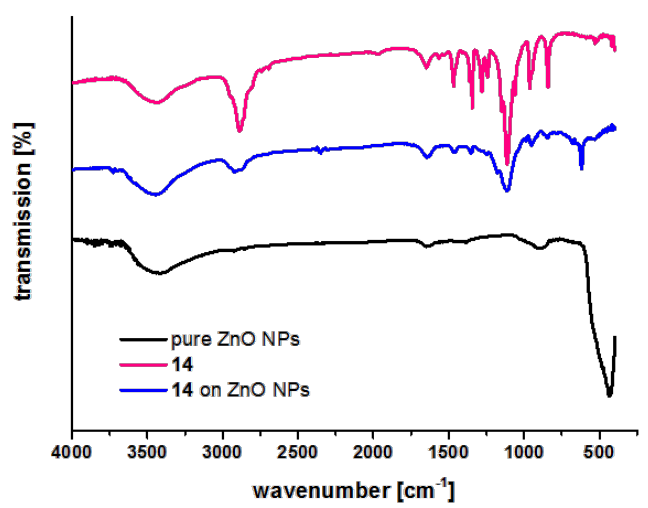

C
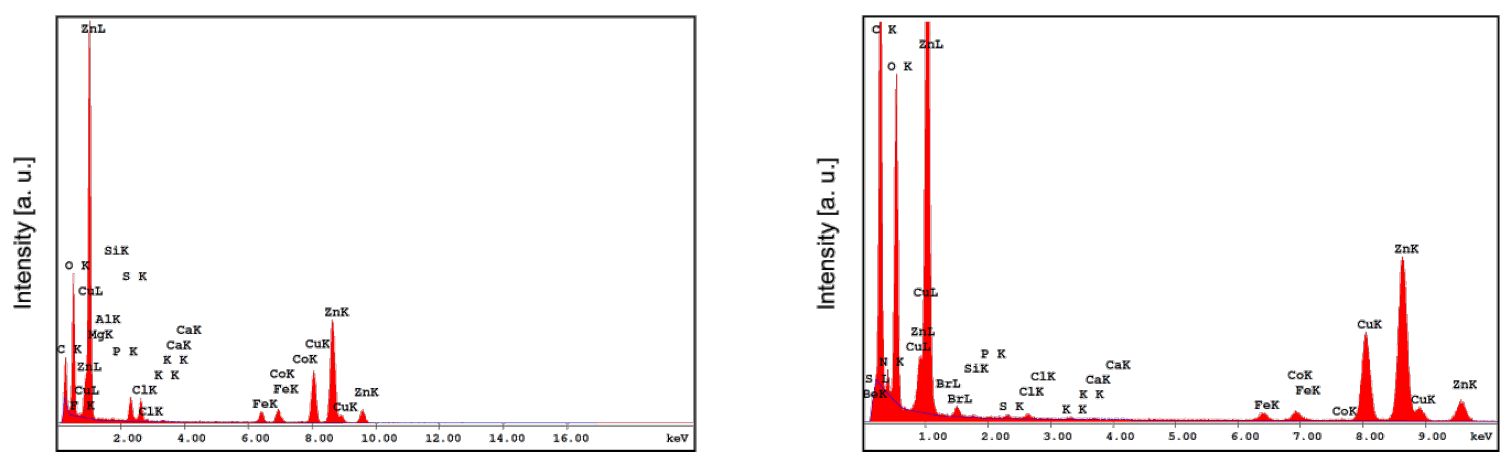

Figure 4: A) TGA data of catecholates 3, 13 and 14 immobilized on ZnO NPs: pure ZnO NPs treated with MOPS buffer (black line), bromo-triscatecholate 13 on ZnO NPs (after washing with water and $\mathrm{MeOH}$, orange line), monomeric PEG-catecholate 14 on $\mathrm{ZnO}$ (after centrifugation, blue line) and tripodal PEG-catecholate 3 on ZnO (after washing with water and MeOH, green line). B) FTIR spectra of pure ZnO NPs (before immobilization, black line), monomeric PEG-catecholate 14 (pink line) and monomeric PEG-catecholate 14 immobilized on ZnO NPs (blue line). C) EDX spectrum of pure ZnO NPs. D) EDX spectrum of bromo-triscatecholate 13 immobilized on $\mathrm{ZnO}$.

loading of $86 \mathrm{wt} \%$. This indicates that a large fraction of $\mathbf{1 4}$ is already lost during the first washing procedure, reflecting the reversible binding of monomeric catecholates to metal oxides, as mentioned above. Successful immobilization was also confirmed by IR as showcased for monomeric PEG-catecholate 14 in Figure 4B (for IR spectra of immobilized trimeric catecholates 3 and $\mathbf{1 3}$ see Supporting Information File 1).

This effect is increasingly important if the coated particles are handled in aqueous solution. After three successive rounds of washing with water and $\mathrm{MeOH}$, almost all of the monomeric PEG-catecholate $\mathbf{1 4}$ is lost from the particles as determined by TGA (Figure 5A) and confirmed qualitatively by comparison of the different intensity of the carbon peaks in the EDX spectra of monomer 14 and trimer 3 on $\mathrm{ZnO}$ (Figure 5C and D). In contrast, loading of the tripodal PEG-catecholate $\mathbf{3}$ is retained at about $70 \mathrm{wt} \%$. The comparably lower loss of catecholate loading confirms the ability of our triscatecholates to form stable layers on ZnO NPs and parallels our previous observations on $\mathrm{TiO}_{2}$ and stainless steel surfaces [31].

The observed difference in catechol loading has an impact on the stability of the ZnO NPs in water. The TEM images in Figure 6 show the coated particles after three rounds of washing with water and $\mathrm{MeOH}$. Homogenous isolated spherical particles of about $25 \mathrm{~nm}$ diameter are observed for tripodal PEGcatecholate 3 (Figure 6C). This compares well to the expected size of $6 \mathrm{~nm}$ NPs coated with a $5 \mathrm{kDa}$ PEG [50]. In contrast, the particles initially coated with monomeric PEG-catecholate 14 form larger aggregates (Figure 6A). As expected, particles coated with the hydrophobic tripodal catecholate $\mathbf{1 3}$ show the same tendency for aggregation in aqueous solution (Figure 6B).

\section{Conclusion}

We report here the synthesis of new tripodal catecholates as valuable multivalent anchor molecules for immobilization on 
A

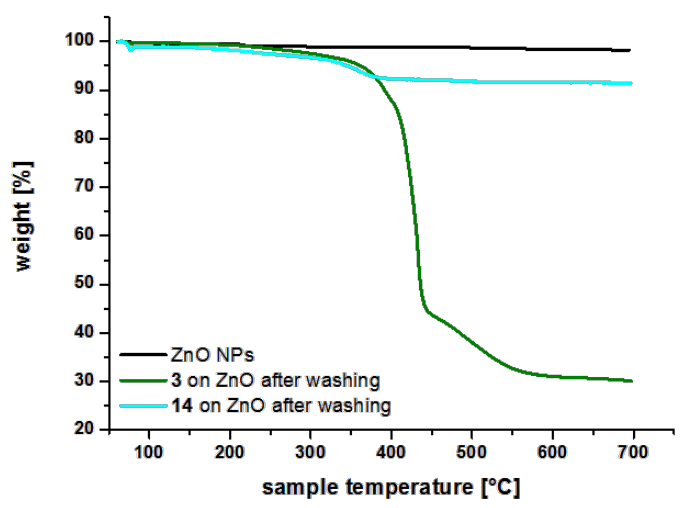

C

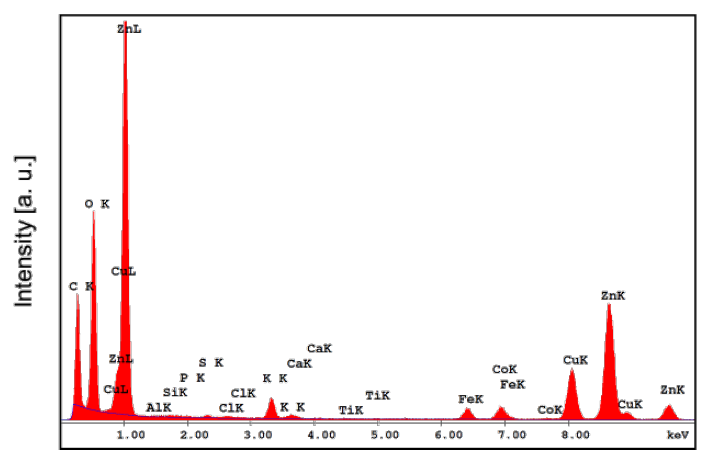

B

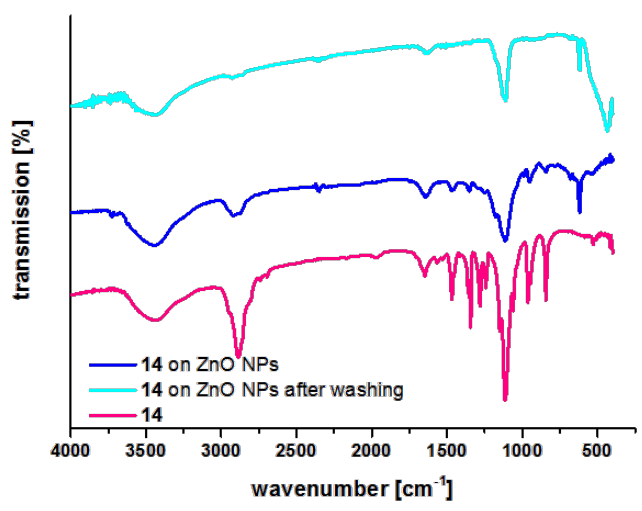

D

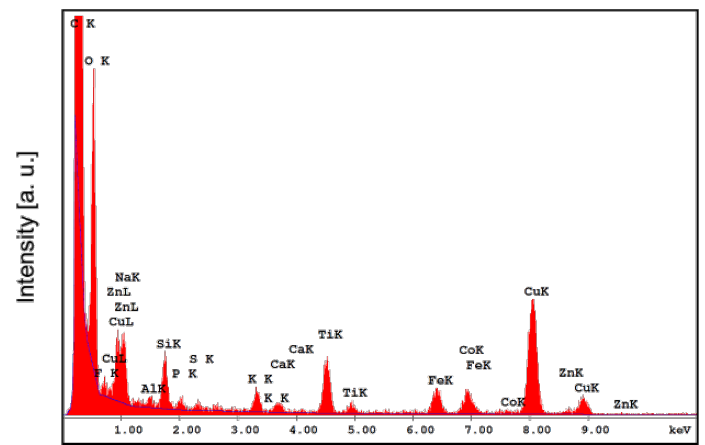

Figure 5: A) TGA data of catecholates 3 and 14 immobilized on ZnO NPs: pure ZnO NPs treated with MOPS buffer (black line), monomeric PEGcatecholate 14 on $\mathrm{ZnO}$ after washing with water and $\mathrm{MeOH}$ for three times (cyan line) and tripodal PEG-catecholate 3 on $\mathrm{ZnO}$ after washing with water and $\mathrm{MeOH}$ for three times (green line). B) FTIR spectra of monomeric PEG-catecholate 14 immobilized on ZnO after washing twice with water and $\mathrm{MeOH}$ (cyan line), monomeric PEG-catecholate 14 immobilized on ZnO after centrifugation from MOPS buffer (blue line) and monomeric PEGcatecholate 14 (pink line). C) EDX spectrum of monomeric PEG-catecholate immobilized on ZnO NPs after washing with water and MeOH. D) EDX spectrum of tripodal PEG-catecholate immobilized on ZnO NPs after washing with water and $\mathrm{MeOH}$.
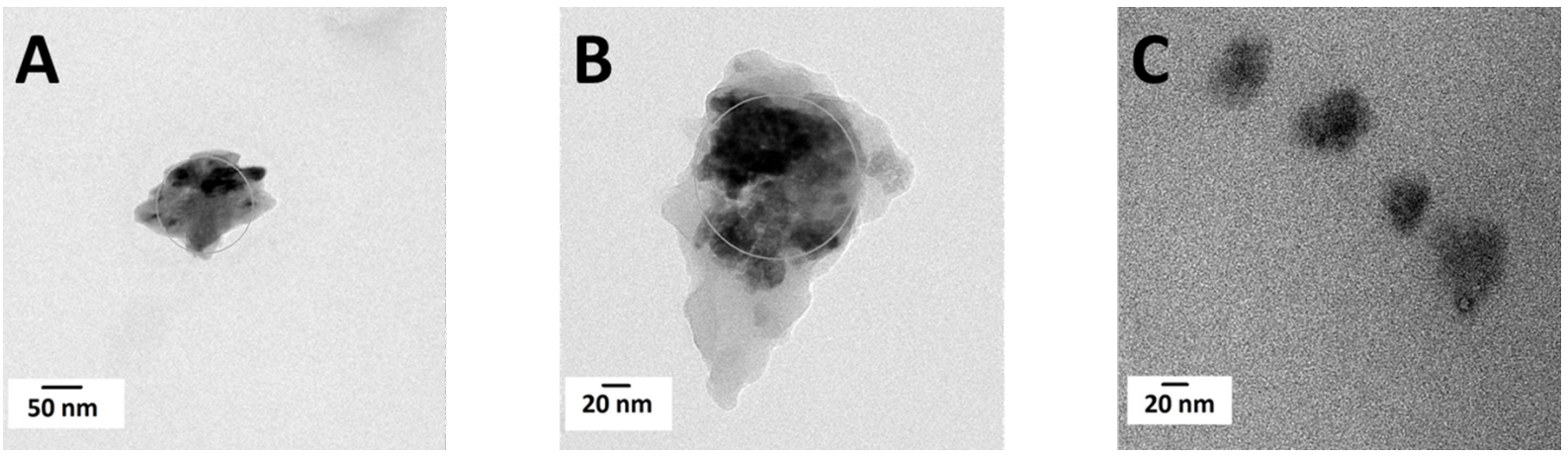

Figure 6: TEM images of ZnO NPs. A) ZnO NPs coated with monomeric PEG-catecholate 14 after washing with water and MeOH for three times. B) ZnO NPs coated with bromo-triscatecholate 13 after washing with water and MeOH for three times. C) ZnO NPs coated with tripodal PEG-catecholate $\mathbf{3}$ after washing with water and $\mathrm{MeOH}$ for three times.

metal surfaces and nanoparticles. These catecholate anchors make use of a biomimetic covalent immobilization concept as found for example in mussel adhesion proteins. Our tripodal catecholate anchors are bifunctional and have been conjugated to various effector molecules such as PEG, a sulfobetaine and an adamantyl group, thus evidencing the feasibility and versatility of the developed approach. The resulting effector-catecholate conjugates are useful for the generation of biopassive 
(stealth) surfaces (PEG and sulfobetaine) or switchable hydrophobic/hydrophilic layers (reversible formation of adamantane/cyclodextrin inclusion complexes) on bulk metal surfaces or NPs.

The potential of these conjugates has been demonstrated through the immobilization of the tripodal PEG-catecholate 3 on $\mathrm{ZnO}$ NPs and a comparison with the monovalent PEG-catecholate 14. The results confirmed a high loading of tripodal PEG-catecholate $\mathbf{3}$ on the particles and the formation of stable catecholate layers in aqueous solution. Immobilization of the monomeric PEG-catecholate $\mathbf{1 4}$ was also successful. However, the monomeric catecholate $\mathbf{1 4}$ is rapidly eliminated by treatment of the coated particles with water, thus highlighting a much lower stability.

In summary, effector conjugates of tripodal catecholates such as $\mathbf{3}$ and $\mathbf{1 3}$ form stable layers on $\mathrm{ZnO}$ NPs even in water. The results reported here confirm our previous studies of tripodal catecholates and their immobilization on $\mathrm{TiO}_{2}$ and stainless steel.

\section{Experimental Synthesis}

The following compounds were synthesized according to literature procedures: 1 [42], 2 [31], 3 [31], 12 [42] 14 [46].

\section{Thermogravimetric analysis}

The TGA data were obtained with a Pyris 1 TGA of Perkin Elmer under Nitrogen gas flow. The samples were heated at $80{ }^{\circ} \mathrm{C}$ isothermally for 10 minutes and subsequently heated from $80{ }^{\circ} \mathrm{C}$ to $700{ }^{\circ} \mathrm{C}$ at a rate of $10{ }^{\circ} \mathrm{C}$ per minute. The experiments were carried out at least two times.

\section{Fourier transformation infrared spectroscopy}

IR spectra were measured on a Jasco FTIR 4100 device as a disc of anhydrous potassium bromide purchased from Merck.

\section{TEM analysis}

For TEM analysis, the functionalized particles were dispersed in $\mathrm{MeOH}$ and dropped onto 400-mesh carbon-coated TEM copper grids. The samples were analyzed using a JEOL JEM1011 microscope, equipped with a LaB6 cathode and operated at $100 \mathrm{kV}$.

\section{HRTEM and EDX analysis}

For high resolution TEM (HRTEM) and energy-dispersive $\mathrm{X}$-ray analysis (EDX), the functionalized particles were dispersed in $\mathrm{MeOH}$ and transferred to carbon-coated TEM grids. The samples were analyzed using a Philips CM 300 microscope, operated at $300 \mathrm{kV}$.

\section{XRD analysis}

For XRD analysis, the functionalized particles were dispersed in $\mathrm{MeOH}$, dropped on a standard crystal Si support. Then the solvent was evaporated. The samples were analyzed using a Philips X'Pert PRO MPD diffractometer ( $\mathrm{Cu} \mathrm{K} \alpha$ radiation, variable entrance slit, Bragg-Brentano geometry, secondary monochromator).

\section{Supporting Information}

\section{Supporting Information File 1}

Experimental procedures, additional analytical data and NMR spectra.

[http://www.beilstein-journals.org/bjoc/content/ supplementary/1860-5397-11-77-S1.pdf]

\section{Acknowledgements}

The opportunity to measure TGA at the Pyris 1 TGA of Perkin Elmer in the division of pharmaceutical technology is appreciated. Support by the HMBF and WI-Bank is greatfully acknowledged.

\section{References}

1. Pujari, S. P.; Scheres, L.; Marcelis, A. T. M.; Zuilhof, H. Angew. Chem., Int. Ed. 2014, 53, 6322-6356. doi:10.1002/anie.201306709

2. Sagiv, J. J. Am. Chem. Soc. 1980, 102, 92-98. doi:10.1021/ja00521a016

3. Flink, S.; van Veggel, F. C. J. M.; Reinhoudt, D. N. J. Phys. Org. Chem. 2001, 14, 407-415. doi:10.1002/poc.372

4. Love, J. C.; Estroff, L. A.; Kriebel, J. K.; Nuzzo, R. G.; Whitesides, G. M. Chem. Rev. 2005, 105, 1103-1170. doi:10.1021/cr0300789

5. Tao, Y. T. J. Am. Chem. Soc. 1993, 115, 4350-4358. doi:10.1021/ja00063a062

6. Hofer, R.; Textor, M.; Spencer, N. D. Langmuir 2001, 17, 4014-4020. doi:10.1021/la001756e

7. Queffélec, C.; Petit, M.; Janvier, P.; Knight, D. A.; Bujoli, B. Chem. Rev. 2012, 112, 3777-3807. doi:10.1021/cr2004212

8. Dalsin, J. L.; Hu, B.-H.; Lee, B. P.; Messersmith, P. B. J. Am. Chem. Soc. 2003, 125, 4253-4258. doi:10.1021/ja0284963

9. Gademann, K.; Kobylinska, J.; Wach, J.-Y.; Woods, T. M. BioMetals 2009, 22, 595-604. doi:10.1007/s10534-009-9234-3

10. Lee, B. P.; Messersmith, P. B.; Israelachvili, J. N.; Waite, J. H. Annu. Rev. Mater. Res. 2011, 41, 99-132. doi:10.1146/annurev-matsci-062910-100429

11. Amstad, E.; Gillich, T.; Bilecka, I.; Textor, M.; Reimhult, E. Nano Lett. 2009, 9, 4042-4048. doi:10.1021/n1902212q

12. Waite, J. H.; Tanzer, M. L. Science 1981, 212, 1038-1040. doi:10.1126/science.212.4498.1038

13. Gillich, T.; Benetti, E. M.; Rakhmatullina, E.; Konradi, R.; Li, W.; Zhang, A.; Schlüter, A. D.; Textor, M. J. Am. Chem. Soc. 2011, 133, 10940-10950. doi:10.1021/ja202760x 
14. Franzmann, E.; Khalil, F.; Weidmann, C.; Schröder, M.; Rohnke, M.; Janek, J.; Smarsly, B. M.; Maison, W. Chem. - Eur. J. 2011, 17, 8596-8603. doi:10.1002/chem.201100715

15. Saville, S. L.; Stone, R. C.; Qi, B.; Mefford, O. T. J. Mater. Chem. 2012, 22, 24909-24917. doi:10.1039/c2jm34902g

16. Morkoç, H.; Özgür, Ü. Zinc Oxide: Fundamentals, Materials and Device Technology; Wiley-VCH: Weinheim, 2009.

17. Kumar, S. S.; Venkateswarlu, P.; Rao, V. R.; Rao, G. N. Int. Nano Lett. 2013, 3, No. 30. doi:10.1186/2228-5326-3-30

18. Özgür, Ü.; Alivov, Ya. I.; Liu, C.; Teke, A.; Reshchikov, M. A.; Doğan, S.; Avrutin, V.; Cho, S.-J.; Morkoç, H. J. Appl. Phys. 2005, 98, 041301. doi:10.1063/1.1992666

19. Shi, X.; Gu, W.; Li, B.; Chen, N.; Zhao, K.; Xian, Y. Microchim. Acta 2014, 181, 1-22. doi:10.1007/s00604-013-1069-5

20. de Lacy Costello, B. P. J.; Ewen, R. J.; Ratcliffe, N. M.; Richards, M. Sens. Actuators, B 2008, 134, 945-952. doi:10.1016/j.snb.2008.06.055

21. Chu, S.; Olmedo, M.; Yang, Z.; Kong, J.; Liu, J. Appl. Phys. Lett. 2008, 93, 181106. doi:10.1063/1.3012579

22. Shahmoradi, B.; Namratha, K.; Byrappa, K.; Soga, K.; Ananda, S.; Somashekar, R. Res. Chem. Intermed. 2011, 37, 329-340. doi:10.1007/s11164-011-0255-5

23. Beretta, A.; Sun, Q.; Herman, R. G.; Klier, K. Ind. Eng. Chem. Res. 1996, 35, 1534-1542. doi:10.1021/ie9505219

24. Wang, Z. L. Mater. Today 2004, 7, 26-33. doi:10.1016/S1369-7021(04)00286-X

25. Weller, H. Philos. Trans. R. Soc., A 2003, 361, 229-240. doi:10.1098/rsta.2002.1136

26. Spanhel, L. J. Sol-Gel Sci. Technol. 2006, 39, 7-24 doi:10.1007/s10971-006-7302-5

27. Ehrentraut, D.; Sato, H.; Kagamitani, Y.; Sato, H.; Yoshikawa, A.; Fukuda, T. Prog. Cryst. Growth Charact. Mater. 2006, 52, 280-335. doi:10.1016/j.pcrysgrow.2006.09.002

28. Dolcet, P.; Casarin, M.; Maccato, C.; Bovo, L.; Ischia, G.; Gialanella, S.; Mancin, F.; Tondello, E.; Gross, S. J. Mater. Chem. 2012, 22, 1620-1626. doi:10.1039/C1JM13301B

29. Buha, J.; Djerdj, I.; Niederberger, M. Cryst. Growth Des. 2007, 7, 113-116. doi:10.1021/cg060623+

30. Famengo, A.; Anantharaman, S.; Ischia, G.; Causin, V.; Natile, M. M.; Maccato, C.; Tondello, E.; Bertagnolli, H.; Gross, S. Eur. J. Inorg. Chem. 2009, 5017-5028. doi:10.1002/ejic.200900506

31. Khalil, F.; Franzmann, E.; Ramcke, J.; Dakischew, O.; Lips, K. S.; Reinhardt, A.; Heisig, P.; Maison, W. Colloids Surf., B 2014, 117, 185-192. doi:10.1016/j.colsurfb.2014.02.022

32. Jeon, S. I.; Lee, J. H.; Andrade, J. D.; De Gennes, P. G. J. Colloid Interface Sci. 1991, 142, 149-158. doi:10.1016/0021-9797(91)90043-8

33. Malisova, B.; Tosatti, S.; Textor, M.; Gademann, K.; Zürcher, S. Langmuir 2010, 26, 4018-4026. doi:10.1021/la903486z

34. Schlenoff, J. B. Langmuir 2014, 30, 9625-9636. doi:10.1021/la500057j

35. Shao, Q.; Jiang, S. Adv. Mater. 2015, 27, 15-26. doi:10.1002/adma.201404059

36. Wei, Q.; Krysiak, S.; Achazi, K.; Becherer, T.; Noeske, P.-L. M.; Paulus, F.; Liebe, H.; Grunwald, I.; Dernedde, J.; Hartwig, A.; Hugel, T.; Haag, R. Colloids Surf., B 2014, 122, 684-692. doi:10.1016/j.colsurfb.2014.08.001

37. Wei, Q.; Becherer, T.; Mutihac, R.-C.; Noeske, P.-L. M.; Paulus, F.; Haag, R.; Grunwald, I. Biomacromolecules 2014, 15, 3061-3071. doi:10.1021/bm500673u

38. Mrksich, M.; Whitesides, G. M. Annu. Rev. Biophys. Biomol. Struct. 1996, 25, 55-78. doi:10.1146/annurev.bb.25.060196.000415
39. Wei, Q.; Becherer, T.; Angioletti-Uberti, S.; Dzubiella, J.; Wischke, C.; Neffe, A. T.; Lendlein, A.; Ballauff, M.; Haag, R. Angew. Chem., Int. Ed. 2014, 53, 8004-8031. doi:10.1002/anie.201400546

40. Pannier, N.; Maison, W. Eur. J. Org. Chem. 2008, 1278-1284. doi:10.1002/ejoc.200701003

41. Nasr, K.; Pannier, N.; Frangioni, J. V.; Maison, W. J. Org. Chem. 2008, 73, 1056-1060. doi:10.1021/jo702310g

42. Maison, W.; Frangioni, J. V.; Pannier, N. Org. Lett. 2004, 6, 4567-4569. doi:10.1021/ol048055j

43. Fleck, C.; Franzmann, E.; Claes, D.; Rickert, A.; Maison, W. Synthesis 2013, 45, 1452-1461. doi:10.1055/s-0033-1338470

44. Yang, W. L.; Fabbri, J. D.; Willey, T. M.; Lee, J. R. I.; Dahl, J. E.; Carlson, R. M. K.; Schreiner, P. R.; Fokin, A. A.; Tkachenko, B. A.; Fokina, N. A.; Meevasana, W.; Mannella, N.; Tanaka, K.; Zhou, X. J.; van Buuren, T.; Kelly, M. A.; Hussain, Z.; Melosh, N. A.; Shen, Z.-X. Science 2007, 316, 1460-1462. doi:10.1126/science.1141811

45. Dodziuk, H. Molecules with Holes - Cyclodextrins. In Cyclodextrines and their complexes; Dodziuk, H., Ed.; Wiley-VCH: Weinheim, 2006; pp 1-30. doi:10.1002/3527608982.ch1

46. Zürcher, S.; Wäckerlin, D.; Bethuel, Y.; Malisova, B.; Textor, M.; Tosatti, S.; Gademann, K. J. Am. Chem. Soc. 2006, 128, 1064-1065. doi:10.1021/ja056256s

47. Pesika, N. S.; Hu, Z.; Stebe, K. J.; Searson, P. C. J. Phys. Chem. B 2002, 106, 6985-6990. doi:10.1021/jp0144606

48. Dange, C.; Phan, T. N. T.; André, V.; Rieger, J.; Persello, J.; Foissy, A. J. Colloid Interface Sci. 2007, 315, 107-115. doi:10.1016/j.jcis.2007.03.068

49. Liu, L.-M.; Li, S.-C.; Cheng, H.; Diebold, U.; Selloni, A. J. Am. Chem. Soc. 2011, 133, 7816-7823. doi:10.1021/ja200001r

50. Rixman, M. A.; Dean, D.; Ortiz, C. Langmuir 2003, 19, 9357-9372. doi:10.1021/la034057l

\section{License and Terms}

This is an Open Access article under the terms of the Creative Commons Attribution License (http://creativecommons.org/licenses/by/2.0), which permits unrestricted use, distribution, and reproduction in any medium, provided the original work is properly cited.

The license is subject to the Beilstein Journal of Organic Chemistry terms and conditions:

(http://www.beilstein-journals.org/bjoc)

The definitive version of this article is the electronic one which can be found at: doi:10.3762/bjoc. 11.77 